$10-1-2019$

\title{
Peer Victimization, Internalizing Problems, and Substance Use in Urban African American Adolescents in Chicago: The Relevance of the Self-Medication Hypothesis
}

Jun Sung Hong

Yi-Ping Hsieh

University of North Dakota, yiping.hsieh@und.edu

Kelly Lynn Clary

Rose Theda

Ryan Russ

See next page for additional authors

\section{How does access to this work benefit you? Let us know!}

Follow this and additional works at: https://commons.und.edu/sw-fac

Part of the Social Work Commons

\section{Recommended Citation}

Jun Sung Hong, Yi-Ping Hsieh, Kelly Lynn Clary, et al.. "Peer Victimization, Internalizing Problems, and Substance Use in Urban African American Adolescents in Chicago: The Relevance of the Self-Medication Hypothesis" (2019). Social Work Faculty Publications. 3.

https://commons.und.edu/sw-fac/3

This Article is brought to you for free and open access by the Department of Social Work at UND Scholarly Commons. It has been accepted for inclusion in Social Work Faculty Publications by an authorized administrator of UND Scholarly Commons. For more information, please contact und.commons@library.und.edu. 


\section{Authors}

Jun Sung Hong, Yi-Ping Hsieh, Kelly Lynn Clary, Rose Theda, Ryan Russ, and Dexter R. Voisin

This article is available at UND Scholarly Commons: https://commons.und.edu/sw-fac/3 


\title{
Peer Victimization, Internalizing Problems, and Substance Use in Urban African American Adolescents in Chicago: The Relevance of the Self-Medication Hypothesis
}

\author{
Jun Sung Hong, PhD \\ Sungkyunkwan University, Department of Social Welfare, Seoul, South Korea, \\ Wayne State University, School of Social Work, Detroit, Michigan \\ Yi-Ping Hsieh, PhD \\ The University of North Dakota, Department of Social Work, Grand Forks, \\ North Dakota \\ Kelly Lynn Clary, MSW \\ The University of Illinois at Urbana-Champaign, School of Social Work, \\ Urbana, Illinois \\ Theda Rose, PhD \\ The University of Maryland Baltimore, School of Social Work, Baltimore, \\ Maryland \\ Ryan Russ, MSW \\ Wayne State University, School of Social Work, Detroit, Michigan

\section{Dexter R. Voisin, PhD} \\ The University of Toronto, Factor-Inwentash Faculty of Social Work, Toronto, \\ Canada
}

The aim of the study was to explore the link between peer victimization and substance use and tested the mediating role of internalizing problems in urban African American adolescents in Chicago. Six hundred and thirty-eight adolescents in Chicago's Southside participated in the study. Results from the hierarchical linear regression analysis showed that youth who reported peer victimization were at risk of internalizing problems. Those who were bullied by their peers were more likely to display internalizing problems, which 
was also significantly associated with substance use. Consistent with the self-medication hypothesis, findings from the study suggest that bullied youth are likely to display internalizing problems and turn to substance use. Implications for mental health practice in school settings are also discussed.

Keywords: adolescents; bullying; mental health; peer victimization; substance use

A frican American adolescents in an impoverished urban neighborhood are beset by numerous socioeconomic disadvantages. For instance, in 2016, $22 \%$ of African Americans live below the poverty level, compared to $12.7 \%$ of all Americans (Semega, Fontenot, \& Kollar, 2017). Also, 31\% of African American under 18 years of age live in poverty compared to $11 \%$ of White children. For adolescents in impoverished urban areas, exposure to violence, such as bullying is often a serious concern. According to the Centers for Disease Control and Prevention, bullying (peer victimization) is defined as a subtype of aggressive behavior that is purposeful and repeatedly perpetrated by an individual or a group of individuals against a target (Gladden, Vivolo-Kantor, Hamburger, \& Lumpkin, 2014, p. 7).

Experiences in peer victimization can contribute to serious health problems, including depression, anxiety, and suicidal thoughts and behavior (Bowes, Joinson, Wolke, \& Lewis, (2015; Holt et al., 2015; Stapinski, Araya, Heron, Montgomery, \& Stallard, 2015). In addition, a large body of the research literature over the years has documented that youth who are victimized by their peers turn to alcohol or drugs as a coping mechanism (e.g., Sullivan, Farrell, \& Kliewer, 2006; Tharp-Taylor, Haviland, \& D’Amico, 2009). The prevalence of alcohol and drugs is significantly lower among African Americans than among Whites and Hispanics, as indicated in several study findings (Courtney \& Polich, 2009; Johnston, O'Malley, Bachman, \& Schulenberg, 2010). However, contrary to these study findings, the U.S. Department of Justice indicated that in 2015, $21 \%$ of African American youth (ages 12-18) nationwide reported that illegal drugs were made available to them on school property (Musu-Gillette, Zhang, Wang, Zhang, \& Oudekerk, 2017). Many African American youth living in poverty find themselves confronted by risk behaviors, such as drug use and drug distribution (see Lambert, Brown, Phillips, \& Ialongo, 2004; Semega et al., 2017; Voisin \& Kim, 2018).

Urban African American youth's disadvantage in the social hierarchy, combined with stressful situations (e.g., peer victimization) and scarce resources can also result in an increasing rate of mental health problems (e.g., depression and anxiety; see GaylordHarden \& Cunningham, 2009; Hammack, Robinson, Crawford, \& Li, 2004; Natsuaki et al., 2007). To manage stressful situations and concomitant mental distress, these youth may have the tendency to turn to alcohol and drugs. Several study findings support the link between peer victimization and substance use; however, few studies to date have explored the mediating role of internalizing problems that might explicate this link, and even fewer studies have focused specifically on urban communities where violence and criminal activities are salient.

Moreover, despite the vast amount of empirical support for the association between peer victimization, internalizing problems, and substance use, only one study to date has examined the interrelations among these variables. Luk, Wang, and Simons-Morton (2010) tested the mediating role of depression in the association between peer victimization and 
substance use in a nationally representative sample of American tenth graders. Results indicate that depression mediated the association between the two variables among females, which appears to support the self-medication hypothesis. A more recent longitudinal study by Earnshaw et al. (2017) also examined the psychological processes whereby peer victimization leads to substance use. The study found that experiences of peer victimization in fifth grade were associated with depressive symptoms in seventh grade, which, in turn, were associated with a higher likelihood of alcohol use. However, it remains unclear whether urban African American adolescents who are bullied by their peers might also self-medicate by turning to alcohol and drugs, considering their low rates of drug use relative to their White peers.

\section{THEORETICAL FRAMEWORK}

The self-medication hypothesis of addictive disorders derives from the idea that one will utilize alcohol or drugs to alleviate negative emotions or pain, rather than using a healthier alternative (Shadur, Hussong, \& Haroon, 2015). The continued and consistent use of alcohol and drugs to rid negative emotions eventually could become a habit over time. The underlying premise of the self-medication hypothesis is that those with a high negative affect will have a higher risk of developing a pattern of problematic use of substances over time (Suh, Ruffins, Robins, Albanese, \& Khantzian, 2008), leading to adverse consequences such as the development of a substance use disorder (Shadur et al., 2015). Findings from several studies with adults and young adult samples support the self-medication hypothesis (Hussong, Hicks, Levy, \& Curran, 2001; Park, Armeli, \& Tennen, 2004; Swendsen et al., 2000). For instance, Park et al. (2004) study, which examined whether college students consumed more alcohol on higher-stress days, found that students consumed more alcohol on days they perceived as more stressful. Swendsen et al. (2000) crosssectional study also found that alcohol consumption was associated with lower levels of nervousness.

In terms of research on adolescents, study findings are inconsistent (Arendt, Rosenberg, Fjordback, \& Brandholdt, 2007; Audrain-McGovern, Rodriguez, \& Kassel, 2009; Shadur et al., 2015; Tomlinson \& Brown, 2012a). Shadur et al. (2015) study found that among adolescents, greater daily fluctuations in feelings of worry (but not sadness) was a predictor of increased substance use, which was consistent with the self-medication hypothesis. Tomlinson and Brown (2012b) also examined whether the self-medication and/or social learning models predicted drinking in a sample of over 400 eighth graders. Also consistent with the self-medication hypothesis, the study found that depression predicted more frequent and heavier alcohol use and solitary drinking. Another study assessed 119 cannabis-dependent adolescents by comparing the participants with lifetime depression and problems controlling violent behavior with those without such problems (Arendt et al., 2007). The findings revealed that adolescents with lifetime depression used cannabis for the same reasons as others, and those with prior depression did not use cannabis as a mean of self-medication (Arendt et al., 2007).

Victims of bullying (particularly those with poor coping skills or self-regulatory processes) are likely to turn to alcohol and drugs as a maladaptive coping strategy or selfmedication mechanism to cope with or anesthetize internal states, such as depressed or anxious feelings, affects, memories, and cognitions) that accompany victimization experiences (see Maniglio, 2015, for a review). For low-income African American adolescents 
who are victims of bullying, a lack of opportunities and resources for reducing the distress that is available to peers of higher income might encourage self-medicating with alcohol or drugs.

\section{THE PRESENT STUDY}

The aim of the present study is to explore the mediating role of internalizing problems in the association between peer victimization and substance use from a sample of urban African American adolescents in Chicago's Southside. The focus of the study is on youth in Chicago's Southside, which is a suitable locale for exploring the link between peer victimization and substance use. In recent years, Chicago's Southside has attracted extensive media attention for its youth violence epidemic (Patton, Lane, Leonard, Macbeth, \& Lee, 2017), such as homicide, which has been reported as the nation's highest rate (Federal Bureau of Investigation, 2013, 2014). Although much less information is available on "less serious forms of violence," such as bullying, it has been documented that between 2005 and 2015, a decreasing rate of peer victimization was reported among youth in suburban and rural communities while no significant pattern of change was reported among those in urban communities (Musu-Gillette et al., 2017). This seems to suggest that peer victimization remains a pervasive problem in urban communities, such as Chicago's Southside. Moreover, in the State of Illinois, the distribution of controlled substances is also a serious problem, as increased use and distribution of cannabis, heroin, prescription drugs, cocaine, and crack cocaine from 2014 to 2015 have been reported (Reichert, Sacomani, Medina, DeSalvo, \& Adams, 2016). According to the Youth Risk Surveillance System, there appears to be an increasing trend of drug use among adolescents in Illinois (KaneWillis et al., 2015). For example, the survey found that from 2007 to 2013, the rate of heroin use increased from $2.5 \%$ to $3.9 \%$ among young people in Illinois, and Chicago was rated as having the highest in the nation for illicit drug use indicators, such as ED visits, drug-related arrests, and African American users (Kane-Willis et al., 2015).

Extending Luk et al. (2010) and Earnshaw et al. (2017) findings, the present study examines the mediating role of internalizing problems in the association between peer victimization and substance use in a sample of urban African American youth in Chicago's Southside. It is hypothesized that (a) African American youth who are victimized by their peers are at an increased risk of substance use (direct effect), and (b) internalizing problems would mediate the link between peer victimization and substance use (indirect effect).

\section{METHOD}

\section{Sample and Procedure}

Between August 2013 and January 2014, a cross-sectional study, which utilized a purposive sampling, was conducted in Chicago's Southside. The study received approval from the Institutional Review Board at the last author's respective institution, and the study participants were recruited from low-income communities, which comprised predominantly of African American residents where the range of average annual incomes was between $\$ 24,049$ and $\$ 35,946$ (Chicago's average annual income is $\$ 43,628$ ). The percentage of 
single-female-headed households in these communities ranged from $28.9 \%$ to $32.3 \%$ (the average percentage of single-female-headed household in Chicago is 13.9\%). The residents in the communities where the present study was conducted were predominantly lowincome, African Americans. The study sites included three high schools, one youth church group, two community youth programs, and four public venues frequented by youth (e.g., parks, fast food outlets, and movie theaters). The number of adolescents approached at each site and those who enrolled in the study included: schools $(606 / 579)$, community centers (42/38), churches (49/44), and public venues (56/39). The overall response rate was $87 \%$, which was based on the 753 youths who were first invited to participate in the study.

The eligibility criteria for the study participation were as follows: (a) youth selfidentified as African American and (b) youth between the ages of 13-24 years (which represents early to late adolescence). Those under 18 years old were required to provide informed assent and have a caregiver who also provided informed consent. Those 18 years old and older independently provided consent to participate in the study.

Flyers, which provide descriptions of the study, were posted at each of the previously mentioned locations and trained research assistants provided information about the study to potential participants in these locations. Each participant was given a detailed letter, which provided an overview of the study, along with parental consent forms. Those who provided signed consent forms were enrolled in the study. Those who were recruited in public venues were only asked to participate if a caregiver was physically present to directly provide consent. When possible, questionnaires were administered in small groups.

All study participants completed the self-administered questionnaire, which was monitored by the research assistants to minimize interruptions and to maintain confidentiality. Those who were recruited from schools, community programs, and churches were provided with a questionnaire in those respective locations in spaces assigned by the venue. The small number of individuals who were recruited in public venues, such as parks and fast food venues were given the questionnaire in a quiet space at or near those venues. The questionnaire lasted up to 45 minutes to complete and each youth was given $\$ 10$ for their participation.

\section{Measures}

Peer victimization was derived from the University of Illinois Victimization Scale (Espelage \& Holt, 2001) and was measured with the question, "How many times you did this activity or how many times these things happened to you in the LAST 30 DAYS," followed by the statements: "Other students picked on me," "Other students made fun of me," "Other students called me names," and "I got hit and pushed by other students." Response options are on a 5-point, Likert scale, ranging from $0=$ never to $4=7$ or more times. The score of peer victimization was calculated by the sum of these four items. Cronbach alpha was .88.

Substance use was measured with the following six questions: "Have you ever taken ecstasy? (Molly, MDMA)," "Have you ever used Lean or Krokodil? (cough syrup, codeine)," "Have you ever had at least one drink of alcohol?," "Have you ever drunk 5 or more drinks of alcohol in a row within a couple of hours?," "Have you ever used marijuana? (blunts, pot, weed)," and "Have you ever used crack or cocaine?" Response options for each item are $0=$ no, $1=$ yes. The score of substance use was calculated by the sum of these six items. 
Internalizing problems were measured with a question asking the participants to "select the choice that best describes how much that problem has distressed or bothered you during the past 7 days, including today," followed by the statements. Depression was measured with the statements, "Feeling no interest in things," "Feeling lonely," "Feeling blue," "Feeling of worthlessness," "Feeling hopeless about the future," and "Thoughts of ending your life." Anxiety was measured with the statements, "Nervousness or shakiness inside," "Feeling tense or keyed up," "Spells of terror or panic," "Suddenly scared for no reason," "Feeling so restless you couldn't sit still," and "Feeling fearful or worried." Both were measured using the University of California at Los Angeles' PTSD Reaction Index (UCLARI) Adolescent Version (Saltzman, Pynoos, Layne, Steinberg, \& Aisenberg, 2001). Response options are on a 5-point Likert scale, ranging from $0=$ not at all to $4=$ extremely. The scores of depression and anxiety were calculated by the sum scores. Cronbach alphas were .83 and .82 , respectively. Depression was highly correlated with anxiety $(r=.82)$. The score of the internalizing problem was calculated by the mean of depression and anxiety.

Covariates for the study included age (ages 12-22), sex $(1=$ boys, $0=$ girls), and family substance use ("How many adults in your household have a problem with substance abuse? [e.g., coke, crack, marijuana, alcohol]"; $0=$ none, $4=4$ or more ).

\section{Analysis}

To test the self-medication hypothesis, a series of analyses were performed to examine the mediating effects of internalizing problems on the relationship between peer victimization and adolescent substance use. The most common method to test mediation is the hierarchical linear regression approach developed by Baron and Kenny (1986). The basic mediation model is defined by three regression equations that are evaluated sequentially in four models. First, there is a significant relationship between the predictor (peer victimization) and the outcome (substance use). Second, the predictor is related to the mediator (internalizing problem). Third, the mediator is related to the outcome variable. In addition, the strength of the relationship between the predictor and the outcome is significantly reduced when the mediator is added to the model. Given the study sample size $(n=638)$, there was sufficient power to detect medium to large mediated effects (MacKinnon, Lockwood, Hoffman, West, \& Sheets, 2002). The mediational hypothesis tested was that urban African American adolescents who experienced peer victimization were more likely to have an internalizing problem, and those who have internalizing problems are at a higher risk of substance use. Finally, it was hypothesized that once the relationship between internalizing problem and substance use was accounted for, there would be a weaker relationship between peer victimization and substance use. Thus, the internalizing problem was hypothesized to be a partial mediator. In addition, three covariates (sex, age, and family substance use) were included in the analysis to reduce unexplained variability in the outcome variable (substance use). The Sobel test was used to confirm the mediation (see Sobel, 1982; Figure 1).

\section{RESULTS}

\section{Descriptive Statistics and Correlations}

Table 1 shows the means, standard deviations, and bivariate correlations for peer victimization, substance use, internalizing problem, sex, age, and family substance use. As expected, peer victimization was positively correlated with the internalizing problem and substance 


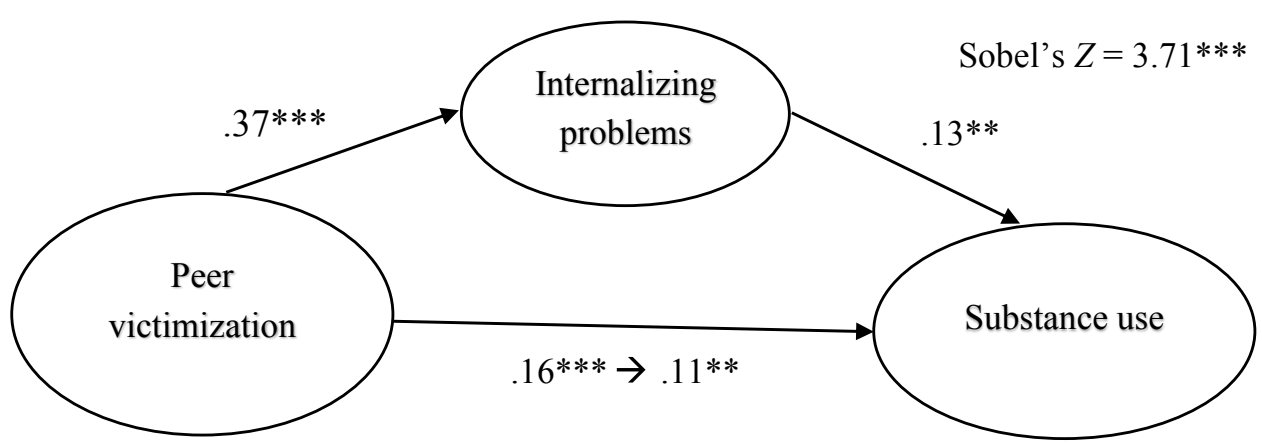

FIGURE 1. The mediation model of internalizing problems on peer victimization and substance use

TABLE 1. Bivariate Correlations, Means, and Standard Deviations for Variables in the Models $(n=638)$

\begin{tabular}{lcccccc}
\hline & 1 & 2 & 3 & 4 & 5 & 6 \\
\hline 1. Peer victimization & - & & & & & \\
2. Substance use & $.15 * *$ & - & & & & \\
3. Internalizing problems & $.36 * *$ & $.15 * *$ & - & & & \\
4. Sex & -.01 & $.14 * *$ & $-.11 * *$ & - & & \\
5. Age & $-.13 * *$ & $.21 * *$ & -.02 & $.14 * *$ & - & \\
6. Family substance use & .05 & $.18 * *$ & $.10 *$ & $.09 *$ & $.08 *$ & - \\
Mean & 2.18 & 1.26 & 4.06 & - & 15.84 & .20 \\
$S D$ & 3.21 & 1.32 & 4.44 & - & 1.41 & .60 \\
\hline
\end{tabular}

$* p<.05 . * * p<.01$

Note. $S D=$ standard deviation; Codes for sex are $1=$ male, $0=$ female.

use. In addition, the internalizing problem was positively correlated with substance use. Moreover, sex, age, and family substance use were positively correlated with adolescent substance use, while age was negatively correlated with peer victimization. About $46 \%$ of the sample were boys and 54\% were girls, and the average age was 16 . About $12.3 \%$ of the sample had at least one of their adult family members with substance use problems. About $57 \%$ of the sample did not experience peer victimization in the last 30 days, and $40 \%$ of the sample did not use substances. Boys reported higher levels of substance use $(t=3.56$, $p<.001)$ and lower levels of internalizing problem $(t=-2.90, p<.01)$ than girls. No sex difference was found in peer victimization.

\section{Mediating Effect of Internalizing Problems}

To test for mediation, three regression equations were run for analysis. First, peer victimization was significantly associated with substance use (the outcome; $\beta=.16, p<.001$ ), after controlling for covariates (sex, age, and family substance use). Second, the result also indicated a significant relationship between peer victimization and internalizing problems 
(mediator; $\beta=.37, p<.001$ ). Third, the result indicated that the strength of the relationship between peer victimization and substance use was significantly reduced when the internalizing problem was added to the model $(\beta=.11, p<.01)$. Therefore, internalizing problems partially mediated the effect of peer victimization on substance use. The Sobel test also supported the finding of the mediating effect $(Z=3.71, p<.001)$. In sum, the results supported the hypothesis that youth who experienced peer victimization had higher levels of internalizing problem and substance use and identified the mediating effects of the internalizing problem on the link between peer victimization and substance use. Adolescents who experienced peer victimization were more likely to have internalizing problems, and the internalizing problems, in turn, increased the probability of substance use (Table 2).

\section{DISCUSSION}

The aim of the present study was to explore the mediating role of internalizing problems in the association between peer victimization and substance use in a sample of urban African American adolescents in Chicago's Southside. Consistent with the first hypothesis and past research, the study results indicated that adolescents who reported peer victimization were more likely to display internalizing problems (see Reijntjes, Kamphiuis, Prinzie, \& Telch, 2010; Zwierzynska, Wolke, \& Lereya, 2013), which clearly suggests that there are psychological consequences of being victimized, particularly among adolescents in low-resourced urban areas. Moreover, this finding is consistent with Nadeem and Graham's (2005) findings, which suggest that African American youth who were perceived as victims by their peers had elevated depressed mood. A positive association between peer victimization and internalizing problems, most notably, depression, has been established in the research literature. For urban African Americans, frequent experiences in victimization are not uncommon in their community and can induce feelings of hopelessness. Consequently, these youth may experience negative self-appraisal and psychological distress, such as depression and anxiety.

TABLE 2. Testing the Mediating Effects of Internalizing Problems on Substance Use $(n=638)$

\begin{tabular}{|c|c|c|c|c|c|c|c|c|c|}
\hline \multirow[b]{3}{*}{ Predictors } & \multicolumn{3}{|c|}{ Model 1} & \multicolumn{3}{|c|}{ Model 2} & \multicolumn{3}{|c|}{ Model 3} \\
\hline & \multicolumn{3}{|c|}{ Substance use } & \multicolumn{3}{|c|}{ Internalizing problems } & \multicolumn{3}{|c|}{ Substance use } \\
\hline & $B$ & SE & $\beta$ & $B$ & SE & $\beta$ & $B$ & $\mathrm{SE}$ & $\beta$ \\
\hline Peer victimization & .07 & .02 & $.16^{*}$ & .50 & .05 & $.37 *$ & .05 & .02 & $.11 * *$ \\
\hline Sex & .24 & .11 & $.09 * * *$ & -1.06 & .34 & $-.12 * *$ & .29 & .11 & $.11 * *$ \\
\hline Age & .18 & .04 & $.20 *$ & .14 & .12 & .04 & .18 & .04 & $.19 *$ \\
\hline Family substance use & .34 & .09 & $.15^{*}$ & .55 & .28 & .08 & .33 & .09 & $.15^{*}$ \\
\hline Internalizing problems & & & & & & & .04 & .01 & $.13^{* *}$ \\
\hline
\end{tabular}

${ }^{*} p<.001 . * * p<.01 . * * * p<.05$.

Note. Each column is a regression equation that predicts the criterion at the top of the column. Sex was dummy-coded such that $0=$ female and $1=$ male. 
Also, in line with the second hypothesis, the present study findings revealed that internalizing problems, in turn, increased the likelihood of substance use. Congruent with Luk et al. (2010) and Earnshaw et al. (2017) findings, which indicated that depression mediated the association between peer victimization and substance use, the present study showed that internalizing problems was also a mediator among urban African American youth sample. This finding also supports the self-medication hypothesis, which proposes that adolescents may turn to alcohol or drugs to reduce negative moods of emotions, such as depression or anxiety (Shadur et al., 2015). The prevalence of alcohol and drugs are lower among African American adolescents, relative to adolescents of other racial or ethnic groups. However, African American youth in urban areas where criminal activities are prominent may be at an elevated risk of turning to drugs when they are confronted with stressors (e.g., peer victimization) and concomitant psychological distress (e.g., internalizing problems).

Although sex differences were not a focus of the present study, descriptive results showed that boys reported a higher level of substance use and lower level of internalizing problems compared to girls. Empirical study findings on sex differences in substance use are equivocal; however, our finding is consistent with other studies that have reported an increased and higher use among males during middle and late adolescence (e.g., Chen \& Jacobson, 2012). Urban African American adolescents consistently encounter opportunities to engage in risky behaviors, such as drug use (e.g., Lambert et al., 2004). Males, as compared to females, might have greater freedom to explore their neighborhood environment (Furstenberg \& Hughes, 1997), which gives them more access to utilize drug use as a maladaptive coping strategy. Further, in addition to the self-medication hypothesis, there are other possibly salient theoretical models, such as social learning models that might explain male adolescents' use of substances. That is, given their greater access to and freedom in their neighborhood, boys could have increased opportunities to observe and engage with peers, role models, or others who may be using substances which, in turn, may encourage their use (see Akers, 1977; Petraitis, Flay, \& Miller, 1995; Tomlinson \& Brown, 2012a).

Concomitantly, previous research consistently shows that boys are less likely to report internalizing problems than girls (see Kessler et al., 2012; Schwinn, Schinke, \& Trent, 2010). Many explanations for gender differences in internalizing problems have been proposed, particularly for depressive symptoms. However, Nolen-Hoeksema (2001) suggested that the differences are due to multiple level factors, including biological, interpersonal, and psychological (i.e., greater ruminations among girls) responses to stress. Scholars have also proposed an integrative model, which includes affective, biological, and cognitive vulnerabilities that, in the presence of negative life events, can elevate depressive symptoms among girls (Hyde, Mezulis, \& Abramson, 2008). Generally, these findings suggest that sex differences need to be considered in the development and implementation of behavioral health interventions for urban African American youth.

\section{Limitations}

There are several limitations of the present study. All the data are cross-sectional and thus there is no temporal precedence for the ordering of the variables. This is further compounded by the fact that the outcome was measured as "lifetime" (ever) use, whereas the predictor is "last 30 days" and the mediator is "last 7 days." Because of this, there is also the possibility that peer victimization may mediate the relationship between substance use 
and internalizing problems. Future research might longitudinally examine whether internalizing problems mediate the link between peer victimization and substance use over time within the same time frame.

Also, the measures in the study, which relied on self-reports, are subject to biased reporting. In relations to the measures, the substance use measures in the study are limited in that only a few numbers of drugs were considered. Internalizing problems measured in the current study only considered depressive symptoms and anxiety, although they encompass a wide range of emotional and behavioral problems, such as low self-esteem, hopelessness, trauma, and stress-related disorders (Regier, Kuhl, \& Kupfer, 2013). Researchers might build on the present findings by including a wider range of internalizing problems and substance use and how they might mediate the peer victimization-substance use link.

Furthermore, other variables that might be relevant to the self-medication hypothesis, such as delinquent behavior, socioeconomic study, and the role of sex were not considered in the study. The self-medication hypothesis posits that drugs are perceived as means to relieve a wide range of psychological suffering, including depressive symptoms and anxiety (Halfors, Waller, Bauer, Ford, \& Halpern, 2005; Khantzian, 2003). However, it has also been argued that the self-medication hypothesis encompasses not only internalizing problems, but also negative emotions or a negative outward view, as well as within-person factors related to the risk of drug use (see Hussong, Gould, \& Hersh, 2008). Future research might, for example, explore whether bullied adolescents might self-medicate by displaying problem behaviors or by affiliating with peers who engage in drug use.

Additionally, several studies have reported sex difference in the relationship between peer victimization and substance use (see Luk et al., 2010; Valdebenito, Ttofi, \& Eisner, 2015) and in the relationship between peer victimization and internalizing problems (see Kaltiala-Heino, Frojd, \& Marttunen, 2010; Sweeting, Young, West, \& Der, 2006). Researchers might build on this study by testing whether there are sex differences in the relevance of the self-medication hypothesis in the association between peer victimization, internalizing problems, and drug use.

And finally, there was a wide age range for youth in this study (ages 12-22), which might raise the question whether there were age differences in peer victimization and substance use and whether there a difference in drug availability between youth in school (age 18) compared to youth out of school (ages 19-22).

\section{Implications for Practice}

These limitations aside, the present study has implications for mental health practitioners. The study findings support the growing evidence of the harmful consequences for adolescents who are bullied; thus, highlight the importance of development, implementation, and evaluation of bullying and substance use prevention programs. Anti-bullying programs have been widely implemented in U.S. school districts; however, a recent meta-analytic study found that while these programs appear to be effective among children in seventh grade and below, there was reversal in efficacy among older adolescents, especially those in high school (Yeager, Fong, Lee, \& Espelage, 2015). In addition, although more intensive programs such as those that consist of parent meetings, firm disciplinary methods, and improved playground supervision have demonstrated efficacy (see Ttofi \& Farrington, 2011), it is uncertain whether intensive programs are sustainable in urban school districts, which typically have inadequate funding and resources. However, considering that urban 
youth are often confronted with violence both within and outside their school, it is imperative that mental health practitioners in urban schools assess youth for victimization experiences both within and outside the school. Moreover, researchers have demonstrated that there are resilient youth who possess the ability to withstand adversarial conditions (e.g., poverty, violence in the neighborhood) that could lead to peer victimization. In addition to assessing and identifying risk factors, it is essential that practitioners in schools assist victims of bullying in developing resiliency by helping them negotiate risks in stressful situations in order for them to cope more effectively.

The present study findings also have implications for addressing peer victimization within a community context. Professionals working with youth might consider working with community-based organizations, local community centers, or local chapters of national organizations (e.g., boys and girls club). These are important settings that can facilitate positive youth development. Positive youth development emphasizes a strengthbased approach to the promotion of positive outcomes (Tebes et al., 2007). Community settings that take positive youth development into consideration can reinforce adaptive coping strategies. Professionals working with youth in community settings or organizations can also engage local communities through seminars, training, and events to help raise awareness of peer victimization and substance use.

Professionals might also consider working with religious organizations, such as churches, which have established a long history of addressing issues related to child welfare and adolescent development by rallying support for legislation that strengthens child and adolescent-protective legislation and addresses violence in the community (see Robinson \& Hanmer, 2014). Faith-based organizations are also a long-standing resource in many African American communities, providing physical, emotional, civic, and spiritual support for African American families (Taylor, Chatters, \& Levin, 2004) and serving as a key socialization agent for African American youth (Ball, Armistead, \& Austin, 2003). Religious involvement provides opportunities for youth in gaining psychological and emotional support (Ellison, Musick, \& Henderson, 2008) and forming positive peer and adult connections (Smith, 2003) in an environment where there are shared values and beliefs (Milot \& Ludden, 2009). Research has also documented a positive association between religious involvement and better psychosocial adjustment among African American youth (Rose, Joe, Shields, \& Caldwell, 2014; Wong, Rew, \& Slaikeu, 2006). Thus, religious organizations could function as an important context for local and national advocacy for antibullying legislation as well as provide direct support to adolescents to help foster more adaptive coping mechanisms. Youth workers can also help these organizations partner with schools and other community organizations in a larger effort to address peer victimization among urban African American adolescents.

If practitioners are to effectively mitigate the negative outcomes of peer victimization such as substance use, appropriate levels of attention must be paid to the underlying forces at play. As evidenced by the study findings, which support the self-medication hypothesis, practitioners need to recognize that experiences in peer victimization can result in internalizing symptoms, which subsequently manifest risky behaviors, such as substance use. Thus, preventing adolescent substance use requires psychosocial interventions for youth depression and anxiety. A review of research on psychosocial treatment for child and adolescent depression concluded that a combination of cognitive-behavioral therapy and interpersonal psychotherapy are effective in treating adolescent depression (Weersing, Jeffreys, Do, Schwartz, \& Bolano, 2017). Further, cognitive-behavioral therapy has also been found 
to be an effective treatment approach for adolescents with an anxiety disorder (CartwrightHatton, Roberts, Chitsabesan, Fothergill, \& Harrington, 2004; Higa-McMillan, Francis, Rith-Najarian, \& Chorpita, 2016). To effectively intervene, the first essential model is to have a standardized and efficient assessment tool for screening internalizing symptoms, which is needed to aid treatment and intervention efforts (Chan, Dennis, \& Funk, 2008).

Substance abuse among urban African American adolescents might be better described as a symptom than the illness, as substance use may be perceived as a coping mechanism for victimization and internalizing problems. Effectively addressing depression and anxiety are a crucial part of the substance use treatment process. In addition, treatment and prevention of substance use in urban schools will require strategies that target both the problem of the individual (e.g., peer relationships) as well as social and economic conditions that may reinforce victimization and mental health problems (Perron, Gotham, \& Cho, 2008).

\section{CONCLUSION}

More generally, the present study findings suggest that substance use rarely exists in a vacuum, as there are often factors that need to be considered. Consistent with the selfmedication hypothesis, although the association between peer victimization and substance use have been found in the empirical literature, rarely do youth who experience victimization immediately turn to drugs. Rather, bullied youth are likely to follow complex pathways, experiencing psychosocial problems before turning to drugs as a coping mechanism (see Bender, 2010). If mental health practitioners in the school setting are to effectively address the needs of their clients, they must look beyond addressing the presenting problem exclusively. They also need to consider the relationships between the presenting problems and contributing factors, which would ultimately contribute to a more effective treatment plans in schools.

\section{REFERENCES}

Akers, R. L. (1977). Deviant behavior: A social learning approach (2nd ed.). Belmont, CA: Wadsworth.

Arendt, M., Rosenberg, R., Fjordback, L., \& Brandholdt, J. (2007). Testing the self-medication hypothesis of depression and aggression in cannabis-dependent subjects. Psychological Medicine, 37, 935-945. doi:10.1017/S0033291706009688

Audrain-McGovern, J., Rodriguez, D., \& Kassel, J. D. (2009). Adolescent smoking and depression: Evidence for self-medication and peer smoking mediation. Addiction, 104, 1743-1756. doi:10.1111/j.1360-0443.209.02617.x

Ball, J., Armistead, L., \& Austin, B. J. (2003). The relationship between religiosity and adjustment among African-American, female, urban adolescents. Journal of Adolescence, 26, 431-446. doi:10.1016/S0140-1971(03) 00037-X

Baron, R. M., \& Kenny, D. A. (1986). The moderator-mediator variable distinction in social psychological research: Conceptual, strategic, and statistical considerations. Journal of Personality and Social Psychology, 51, 1173-1182. doi:10.1037/0022-3514.51.6.1173

Bender, K. (2010). Why do some maltreated youth become juvenile offenders? A call for further investigation and adaptation of youth services. Children and Youth Services Review, 32, 466-473. doi:10.1016/j.childyouth.2009.10.022 
Bowes, L., Joinson, C., Wolke, D., \& Lewis, G. (2015). Peer victimisation during adolescence and its impact on depression in early adulthood: Prospective cohort study in the United Kingdom. British Medical Journal, 350, 1-9. doi:10.1136/bmj.h2469

Cartwright-Hatton, S., Roberts, C., Chitsabesan, P., Fothergill, C., \& Harrington, R. (2004). Systematic review of the efficacy of cognitive behaviour therapies for childhood and adolescent anxiety disorders. British Journal of Clinical Psychology, 43, 421-436. doi: 10.1348/0144665042388928

Chan, Y. F., Dennis, M. L., \& Funk, R. R. (2008). Prevalence and comorbidity of major internalizing and externalizing problems among adolescents and adults presenting to substance abuse treatment. Journal of Substance Abuse Treatment, 34, 14-24. doi:10.1016/j.jsat.2006.12.031

Chen, P., \& Jacobson, K. C. (2012). Developmental trajectories of substance use from early adolescence to young adulthood: Gender and racial/ethnic differences. Journal of Adolescent Health, 50, 154-163. doi:10.1016/j.jadohealth.2011.05.013

Courtney, K. E., \& Polich, J. (2009). Binge drinking in young adults: Data, definitions, and determinants. Psychological Bulletin, 135, 142-156. doi:10.1037/a0014414

Earnshaw, V. A., Elliott, M. N., Reisner, S. L., Mrug, S., Windle, M., Emery, S. T., . . Schuster, M. A. (2017). Peer victimization, depressive symptoms, and substance use: A longitudinal analysis. Pediatrics, 139, e20163426. doi:10.1542/peds.2016-3426

Ellison, C. G., Musick, M. A., \& Henderson, A. K. (2008). Balm in Gilead: Racism, religious involvement, and psychological distress among African-American adults. Journal for the Scientific Study of Religion, 47, 291-309. doi:10.1111/j.1468-5906.2008.00408.x

Espelage, D. L., \& Holt, M. K. (2001). Bullying and victimization during early adolescence: Peer influences and psychosocial correlates. Journal of Emotional Abuse, 2, 123-142. doi:10.1300/J135v02n02_08

Federal Bureau of Investigation. (2013). Crime in the United States, 2012. Retrieved from https://www.fbi.gov/about-us/cjis/ucr/crime-in-the-u.s/2012/crime-in-the-u.s.-2012/ tables/8tabledatadecpdf/table8-state-cuts/table_8_offenses_known_to_law_enforcement_by_ illinois_by_city_2012.xls

Federal Bureau of Investigation. (2014). Crime in the United States, 2013. Retrieved from https:// www.fbi.gov/about-us/cjis/ucr/crime-in-the-u.s/2013/crime-in-the-u.s.-2013

Furstenberg, F. F., \& Hughes, M. E. (1997). The influence of neighborhoods on children's development: A theoretical perspective and a research agenda. In J. Brooks-Gunn, G. J. Duncan, \& J. L. Aber (Eds.), Neighborhood poverty: Policy implications in studying neighborhoods (Vol. 2, pp. 23-47). New York, NY: Russell Sage Foundation.

Gaylord-Harden, N. K., \& Cunningham, J. A. (2009). The impact of racial discrimination and coping strategies on internalizing symptoms in African American youth. Journal of Youth and Adolescence, 38, 532-543. doi:10.1007/s10964-008-9377-5

Gladden, R. M., Vivolo-Kantor, A. M., Hamburger, M. E., \& Lumpkin, C. D. (2014). Bullying surveillance among youths: Uniform definitions for public health and recommended data elements, version 1.0. Atlanta, GA: National Center for Injury Prevention and Control, Centers for Disease Control and Prevention and U.S. Department of Education.

Halfors, D. D., Waller, M. A., Bauer, D., Ford, C. A., \& Halpern, C. T. (2005). Which comes first in adolescence? Sex and drugs or depression? American Journal of Preventive Medicine, 29, 163-170. doi:10.1016/j.amepre.2005.06.002

Hammack, P. L., Robinson, W. L., Crawford, I., \& Li, S. T. (2004). Poverty and depressed mood among urban African-American adolescents: A family stress perspective. Journal of Child and Family Studies, 13, 309-323. doi:10.1023/B:JCFS.0000022037.59369.90 
Higa-McMillan, C. K., Francis, S. E., Rith-Najarian, L., \& Chorpita, B. F. (2016). Evidence base update: 50 years of research on treatment for child and adolescent anxiety. Journal of Clinical Child \& Adolescent Psychology, 45, 91-113. doi:10.1080/15374416.2015.1046177

Holt, M. K., Vivolo-Kantor, A. M., Polanin, J. R., Holland, K. M., DeGue, S., Matjasko, J. L., . . . Reid, G. (2015). Bullying and suicidal ideation and behaviors: A meta-analysis. Pediatrics, 135, 1-15. doi:10.1542/peds.2014-1864

Hussong, A. M., Gould, L. A., \& Hersh, M. A. (2008). Conduct problems moderate self-medication and mood-related consequences in adolescents. Journal of Studies on Alcohol and Drugs, 69, 296-307. doi:10.15288/jsad.2008.69.296

Hussong, A. M., Hicks, R. E., Levy, S. A., \& Curran, P. J. (2001). Specifying the relations between affect and heavy alcohol use among young adults. Journal of Abnormal Psychology, 110, 449 461. doi:10.1037/0021-843X.110.3.449

Hyde, J. S., Mezulis, A. H., \& Abramson, L. Y. (2008). The ABCs of depression: Integrating affective, biological, and cognitive models to explain the emergence of the gender difference in depression. Psychological Review, 115, 291-313. doi:10.1037/0033-295X.115.2.291

Johnston, L. D., O’Malley, P. M., Bachman, J. G., \& Schulenberg, J. E. (2010). Monitoring the Future national survey results on drug use, 1975-2009; Volume 1, Secondary school students. Bethesda, MD: National Institute on Drug Abuse. (NIH Publication No. 10-7584)

Kaltiala-Heino, R., Frojd, S., \& Marttunen, M. (2010). Involvement in bullying and depression in a 2-year follow-up in middle adolescence. European Child \& Adolescent Psychiatry, 19, 45-55. doi:10.1007/s00787-009-0039-2

Kane-Willis, K., Aviles, G., Barnett, D., Czechowska, J., Metzger, S., Rivera, R., \& Waites, B. (2015). Diminishing capacity: The heroin crisis and Illinois treatment in a national perspective. Illinois consortium on drug policy at Roosevelt University. Chicago, IL: Roosevelt University, Institute for Metropolitan Affairs, Illinois Consortium on Drug Policy.

Kessler, R. C., Avenevoli, S., Costello, E. J., Georgiades, K., Green, J. G., Gruber, M. J., . . Merikangas, K. R. (2012). Prevalence, persistence, and sociodemographic correlates of DSM-IV disorders in the national comorbidity survey replication adolescent supplement. Archives of General Psychiatry, 69, 372-380. doi:10.1001/archgenpsychiatry.2011.160

Khantzian, E. J. (2003). The self-medication hypothesis revisited: The dually diagnosed patient. Primary Psychiatry, 10, 47-54.

Lambert, S. F., Brown, T. L., Phillips, C. M., \& Ialongo, N. S. (2004). The relationship between perceptions of neighborhood characteristics and substance use among urban African American adolescents. American Journal of Community Psychology, 34, 205-218. doi:10.1007/s10464004-7415-3

Luk, J. W., Wang, J., \& Simons-Morton, B. G. (2010). Bullying victimization and substance use among U.S. adolescents: Mediation by depression. Prevention Science, 11, 355-359. doi:10.1007/s11121-010-0179-0

MacKinnon, D. P., Lockwood, C. M., Hoffman, J. M., West, S. G., \& Sheets, V. (2002). A comparison of methods to test mediation and other intervening variable effects. Psychological Methods, 7, 83-104. doi:10.1037/1082-989X.7.1.83

Maniglio, R. (2015). Association between peer victimization in adolescence and cannabis use: A systematic review. Aggression and Violent Behavior, 25, 252-258. doi:10.1016/j.avb.2015.09.002

Milot, A. S., \& Ludden, A. B. (2009). The effects of religion and gender on well-being, substance use, and academic engagement among rural adolescents. Youth \& Society, 40, 403-425. doi:10.1177/0044118X08316668

Musu-Gillette, L., Zhang, A., Wang, K., Zhang, J., \& Oudekerk, B. A. (2017). Indicators of school crime and safety: 2016. Washington, DC: National Center for Educational Statistics, 
U.S. Department of Education, and Bureau of Justice Statistics, Office of Justice Programs, U.S. Department of Justice.

Nadeem, E., \& Graham, S. (2005). Early puberty, peer victimization, and internalizing symptoms in ethnic minority adolescents. Journal of Early Adolescence, 25, 197-222. doi:10.1177/0272431604274177

Natsuaki, M. N., Ge, X., Brody, G. H., Simons, R. L., Gibbons, F. X., \& Cutrona, C. E. (2007). African American children's depressive symptoms: The prospective effects of neighborhood disorder, stressful life events, and parenting. American Journal of Community Psychology, 39, 163-176. doi:10.1007/s10464-007-9092-5

Nolen-Hoeksema, S. (2001). Gender differences in depression. Current Directions in Psychological Science, 10, 173-176. doi:10.1111/1467-8721.00142

Park, C. L., Armeli, S., \& Tennen, H. (2004). The daily stress and coping process and alcohol use among college students. Journal of Studies on Alcohol and Drugs, 65, 126-135. doi:10.15288/jsa.2004.65.126

Patton, D. U., Lane, J., Leonard, P., Macbeth, J., \& Lee, J. R. S. (2017). Gang violence on the digital street: Case study of a South side Chicago gang member's Twitter communication. New Media \& Society, 19, 1000-1018. doi:10.1177/1461444815625949

Perron, B. E., Gotham, H. J., \& Cho, D. (2008). Victimization among African-American adolescents in substance abuse treatment. Journal of Psychoactive Drugs, 40, 67-75. doi:10.1080/02791072.2008.10399762

Petraitis, J., Flay, B. R., \& Miller, T. Q. (1995). Reviewing theories of adolescent substance abuse: Organizing pieces of the puzzle. Psychological Bulletin, 117, 67-86. doi:10.1037/00332909.117.1.67

Regier, D. A., Kuhl, E. A., \& Kupfer, D. J. (2013). The DSM-5: Classification and criteria changes. World Psychiatry, 12, 92-98. doi:10.1002/wps.20050

Reichert, J., Sacomani, R., Medina, E., DeSalvo, M., \& Adams, S. (2016). Drug trends and distribution in Illinois: A survey of drug task forces. Chicago, IL: Illinois Criminal Justice Information Authority.

Reijntjes, A., Kamphiuis, J. H., Prinzie, P., \& Telch, M. J. (2010). Peer victimization and internalizing problems in children: A meta-analysis of longitudinal studies. Child Abuse \& Neglect, 34, 244252. doi:10.1016/j.chiabu.2009.07.009

Robinson, M., \& Hanmer, S. (2014). Engaging religious communities to protect children from abuse, neglect, and exploitation: Partnerships require analysis of religious virtues and harms. Child Abuse \& Neglect, 38, 600-611. doi:10.1016/j.chiabu.2014.03.018

Rose, T., Joe, S., Shields, J., \& Caldwell, C. H. (2014). Social integration and the mental health of black adolescents. Child Development, 85, 1003-1018. doi:10.1111/cdev.12257

Saltzman, W. R., Pynoos, R. S., Layne, C. M., Steinberg, A. M., \& Aisenberg, E. (2001). Trauma-and grief-focused intervention for adolescents exposed to community violence: Results of a schoolbased screening and group treatment protocol. Group Dynamics: Theory, Research, and Practice, 5, 291-303. doi:10.1037/1089-2699.5.4.291

Schwinn, T. M., Schinke, S. P., \& Trent, D. N. (2010). Substance use among late adolescent urban youths: Mental health and gender influences. Addictive Behaviors, 35, 30-34. doi:10.1016/j.addbeh.2009.08.005

Semega, J. L., Fontenot, K. R., \& Kollar, M. A. (2017). Income and poverty in the United States: 2016. Washington, DC: U.S. Department of Commerce. Retrieved from https://www.census.gov/ content/dam/Census/library/publications/2017/demo/P60-259.pdf 
Shadur, J. M., Hussong, A. M., \& Haroon, M. (2015). Negative affect variability and adolescent self-medication: The role of the peer context. Drug and Alcohol Review, 34, 571-580. doi:10.1111/dar.12260

Smith, C. (2003). Theorizing religious effects among American adolescents. Journal for the Scientific Study, 42, 17-30. doi:10.1111/1468-5096.t01-1-00158

Sobel, M. E. (1982). Asymptotic confidence intervals for indirect effects in structural equation models. In S. Leinhart (Ed.), Sociological methodology 1982 (pp. 290-312). San Francisco, CA: Jossey-Bass.

Stapinski, L. A., Araya, R., Heron, J., Montgomery, A. A., \& Stallard, P. (2015). Peer victimization during adolescence: Concurrent and prospective impact on symptoms of depression and anxiety. Anxiety, Stress, \& Coping: An International Journal, 28, 105-120. doi:10.1080/10615806.2014.962023

Suh, J. J., Ruffins, S., Robins, C. E., Albanese, M. J., \& Khantzian, E. J. (2008). Self-medication hypothesis: Connecting affective experience and drug choice. Psychoanalytic Psychology, 25, 518-532. http://dx.doi.org/10.1037/0736-9735.25.3.518

Sullivan, T. N., Farrell, A. D., \& Kliewer, W. (2006). Peer victimization in early adolescence: Association between physical and relational victimization and drug use, aggression, and delinquent behaviors among urban middle school students. Development and Psychopathology, 18, 119 137. doi:10.1017/S095457940606007X

Sweeting, H., Young, R., West, P., \& Der, G. (2006). Peer victimization and depression in early-mid adolescence: A longitudinal study. British Journal of Educational Psychology, 76, 577-594. doi:10.1348/000709905X49890

Swendsen, J. D., Tennen, H., Carney, M. A., Affleck, G., Willard, A., \& Hromi, A. (2000). Mood and alcohol consumption: An experience sampling test of the self-medication hypothesis. Journal of Abnormal Psychology, 109, 198-204. doi:10.1037/0021-843X.109 .2.198

Taylor, R. J., Chatters, L. M., \& Levin, J. (2004). Impact of religion on mental health and well-being. In Religion in the lives of African Americans: Social, psychological and health perspectives ( $\mathrm{pp}$. 207-226). Thousand Oaks, CA: Sage Publications, Inc.

Tebes, J. K., Feinn, R., Vanderploeg, J. J., Chinman, M. J., Shepard, J., Brabham, T., . . Connell, C. (2007). Impact of a positive youth development program in urban after-school settings on the prevention of adolescent substance use. Journal of Adolescent Health, 41, 239-247. doi:10.1016/j.jadohealth.2007.02.016

Tharp-Taylor, S., Haviland, A., \& D'Amico, E. J. (2009). Victimization from mental and physical bullying and substance use in early adolescence. Addictive Behaviors, 34, 561-567. doi:10.1016/j.addbeh.2009.03.012

Tomlinson, K. L., \& Brown, S. A. (2012a). Self-medication or social learning? A comparison of models to predict early adolescent drinking. Addictive Behaviors, 37, 179-186. doi:10.1016/j.addbeh.2011.09.016

Tomlinson, K. L., \& Brown, S. A. (2012b). Self-medication or social learning? A comparison of models to predict early adolescent drinking. Addictive Behaviors, 37, 179-186. doi:10.1016/j.addbeh.2011.09.016

Ttofi, M. M., \& Farrington, D. P. (2011). Effectiveness of school-based programs to reduce bullying: A systematic and meta-analytic review. Journal of Experimental Criminology, 7, 27-56. doi:10.1007/s11292-010-9109-1

Valdebenito, S., Ttofi, M., \& Eisner, M. (2015). Prevalence rates of drug use among school bullies and victims: A systematic review and meta-analysis of cross-sectional studies. Aggression and Violent Behavior, 23, 137-146. doi:10.1016/j.avb.2015.05.004 
Voisin, D. R., \& Kim, D. H. (2018). "Broken windows": Relationship between neighborhood conditions and behavioral health among low-income African American adolescents. Journal of Health Psychology, 23, 527-537. doi:10.1177/1359105316681064

Weersing, V. R., Jeffreys, M., Do, M. C. T., Schwartz, K. T. G., \& Bolano, C. (2017). Evidence base update of psychosocial treatments for child and adolescent depression. Journal of Clinical Child \& Adolescent Psychology, 46, 11-43. doi:10.1080/15374416.2016.1220310

Wong, Y. J., Rew, L., \& Slaikeu, K. D. (2006). A systematic review of recent research on adolescent religiosity/spirituality and mental health. Issues in Mental Health Nursing, 27, 161-183. doi:10.1080/01612840500436941

Yeager, D. S., Fong, C. J., Lee, H. Y., \& Espelage, D. L. (2015). Declines in efficacy of anti-bullying programs among older adolescents: Theory and a three-level meta-analysis. Journal of Applied Developmental Psychology, 37, 36-51. doi:10.1016/j.appdev.2014.11.005

Zwierzynska, K., Wolke, D., \& Lereya, T. S. (2013). Peer victimization in childhood and internalizing problems in adolescence: A prospective longitudinal study. Journal of Abnormal Child Psychology, 41, 309-323. doi:10.1007/s10802-012-9678-8

Disclosure. The authors have no relevant financial interest or affiliations with any commercial interests related to the subjects discussed in this article.

Correspondence regarding this article should be directed to Jun Sung Hong, PhD, Associate Professor, Wayne State University, School of Social Work, 5447 Woodward Avenue, Detroit, MI 48202. E-mail: f14684@wayne.edu 